\title{
Bridging skill gaps and creating future ready accounting and finance graduates: an exploratory study [version 1; peer
} review: 2 approved]

\author{
Saravanan Muthaiyah (iD) 1, Karen Phang², Sanjaya Sembakutti1 ${ }^{1+}$ \\ ${ }^{1}$ Faculty of Management, Multimedia University, Cyberjaya, Selangor, 63100, Malaysia \\ ${ }^{2}$ CIMA SE Asia Sdn Bhd, AICPA, Bandar Utama, Selangor, 47800, Malaysia \\ ${ }^{+}$Deceased author
}

V1 First published: $06 \operatorname{Sep} 2021,10: 892$

https://doi.org/10.12688/f1000research.72880.1

Latest published: 06 Sep 2021, 10:892

https://doi.org/10.12688/f1000research.72880.1

\section{Abstract}

Background: Changing trends in the use of technology have become an impelling force to be reckoned with for the accounting and finance profession. The curriculum offered in higher learning institutions must be quickly revamped so that students who complete a bachelor's degree are digitally competent upon graduation. With US $\$ 55.3$ billion invested in FinTech in 2019 alone and more than $72 \%$ of accounting jobs being automated, graduates must be trained on digital skills to be future proof. Accounting and finance graduates must be made competent in skills that are related to digital content such as blockchain technology, information assets and autonomous peer to peer systems, to name a few.

Methods: We used a three-phase approach: 1) careful mapping of digital topics taught within the course structure offered at these institutions; 2) review of current best practices and digital learning tools for digital inclusion which was ascertained from literature; and 3) 80 experts in a think tank group were interviewed on antecedents, awareness and problems in relation to digital inclusion within the curriculum to validate our research objective.

Results: Eleven key tools for inclusion in the curriculum were discussed with experts and then mapped to current curriculum offered at institutions. We discovered that less than $5 \%$ of these were being taught. In total, $78 \%$ of experts agreed that digital content is inevitable, $90 \%$ agreed that digital inclusion based on tools that were discussed will yield great benefits for students, and lastly $75 \%$ agreed that giving digital exposure to students must be standard practice. Conclusions: The response from experts confirms that digital inclusion is imperative, but instructors themselves lacked the knowhow of emerging technologies. Only the curriculum of institutions with approved bachelor's programs were included in this research. In our future work we hope to include all institutions and professional

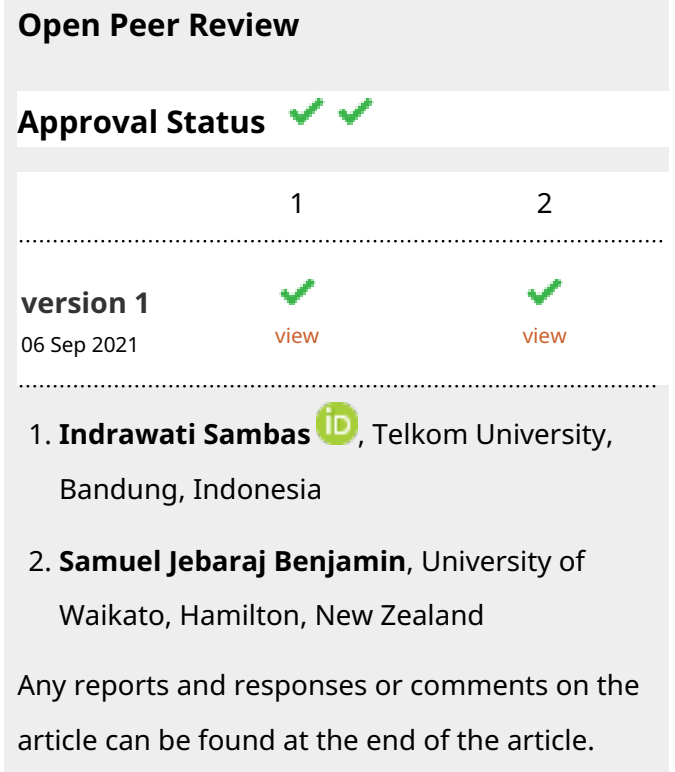


bodies as well.

Keywords

Digital transformation, Pedagogy, FinTech, Teaching and Learning.

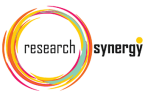

This article is included in the Research Synergy

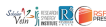

Foundation gateway.

Corresponding author: Saravanan Muthaiyah (saravanan.muthaiyah@mmu.edu.my)

Author roles: Muthaiyah S: Conceptualization, Data Curation, Formal Analysis, Methodology; Phang K: Data Curation, Investigation; Sembakutti S: Investigation, Project Administration

Competing interests: No competing interests were disclosed.

Grant information: The author(s) declared that no grants were involved in supporting this work.

Copyright: @ 2021 Muthaiyah S et al. This is an open access article distributed under the terms of the Creative Commons Attribution License, which permits unrestricted use, distribution, and reproduction in any medium, provided the original work is properly cited.

How to cite this article: Muthaiyah S, Phang K and Sembakutti S. Bridging skill gaps and creating future ready accounting and finance graduates: an exploratory study [version 1; peer review: 2 approved] F1000Research 2021, 10:892 https://doi.org/10.12688/f1000research.72880.1

First published: 06 Sep 2021, 10:892 https://doi.org/10.12688/f1000research.72880.1 


\section{Introduction}

Fintech is a fusion of emerging technologies and finance to provide greater insights to the practice of accounting and finance. However, academic content in the curriculums offered in degree programs do not include these digital topics due to multiple factors, and this has caused education programs to have suffered severe criticism over recent years.

Literature review

Moffitt listed 30 emerging technologies that will have an enormous impact on jobs and artificial intelligence (AI) was the top of that list. ${ }^{1}$ Blockchain has been listed as the $4^{\text {th }}$ most prominent emerging technology that will impact jobs. ${ }^{2}$ Blockchain platforms resolve the core trust issue by maintaining a shared distributed ledger. ${ }^{3,4}$ Smart contracts within a blockchain can enable the transfer of titles, physical goods and assets simultaneously. Given that a sharing economy will be embedded in every financial system by 2020, financial systems will operate like any other sharing economy.

This gives rise to cloud computing which would perhaps have the second highest impact on accounting jobs. ${ }^{5}$ Artificial intelligence (AI) has also found its way into predictive models. ${ }^{6}$ Audit tasks will also benefit from AI, as the use of artificial neural networks (ANN) for audit tasks thus increases the ability to track and uncover control flaws that humans can't. ${ }^{4,7}$ There is a high demand for digital skills, however due to the lack of digital skill sets companies aren't able to hire a skilled tech-savvy financial workforce. ${ }^{8}$ Employers have demonstrated their disappointment as the digital gap widens among finance graduates. ${ }^{9}$ In a study conducted on 200 accounting and finance firms, where 105 graduate students from different universities were evaluated for their digital know-how, results indicated that these graduate students largely lacked in analytical and other digital skills. Hiring personnel equipped with skills in finance-related software, data analytics, and modelling programs is becoming difficult because of the outdated curriculum, which focuses more on traditional and obsolete concepts. ${ }^{4,10}$

Descriptive, prescriptive and predictive accounting

Today's accounting curriculum is focused on descriptive accounting (see Figure 1). ${ }^{3}$ Prescriptive accounting is rather limited, with the exception of managerial and cost accounting only (see Figure 2). For example, assets are still recorded and maintained at cost which is not aligned to fair value accounting principles.

At the operational level most activities can be fully automated. Activities at this level, such as journal entries, are mostly descriptive. The tactical layer requires some level of automation but will mostly be prescriptive (see Figure 3 ).

\section{Course mapping for digital inclusion}

Based on the earlier discussion, we proceeded to attempt to understand how much of these essential digital topics (see Table 1) were embedded in the accounting curriculum, as these tools have been endorsed by the literature. Upon mapping to the existing curriculum of major accredited institutions we found very little or no evidence of these digital tools being embedded into the taught curriculum. Out of 11 teaching technologies or tools we could only partially map one item. Table 1 summarizes our findings.

\section{Study objectives and research questions}

The objective of this section was to ascertain technological content gaps with reference to tools discussed earlier within the accounting curriculum offered by higher learning institutions. Additional research questions that this paper aimed to address were as follows:

- What is the level of awareness of classroom teaching technologies among accounting educators?

- What are the antecedents for technology inclusion into existing Institutions of Higher Learning (IHL) curriculums?

- What are the problems associated with technology implementation?

\section{Methods}

This was an exploratory study with the main focus of understanding how much technological context was covered in the existing accounting curriculum. Throughout the study, Table 2 (detailed description of digital tools) was used as a reference for experts to evaluate and benchmark best practices. A total of 80 individuals, comprising of experts, academicians, program counselors, curriculum experts, program coordinators, subject experts, industry advisory panel members and practitioners were interviewed (with their consent) for feedback. Detailed curriculum and program structures were also reviewed for comparison. The authors Saravanan Muthaiyah and Sanjaya Chamara Sembakutti conducted the interviews; only participants who were willing took part were interviewed, the rest left the hall. The 


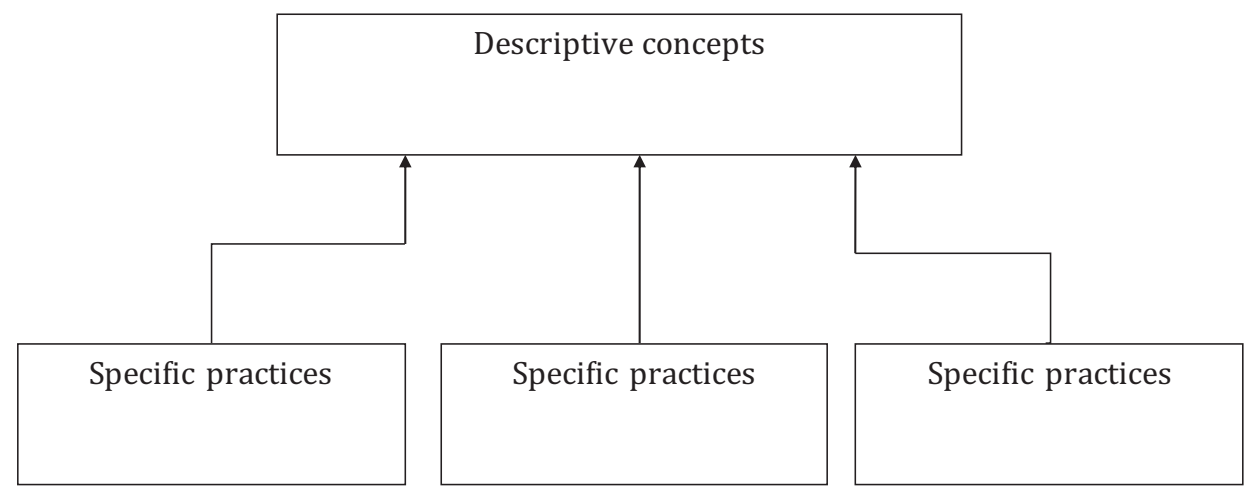

Figure 1. Descriptive approach to the bottom-up approach.

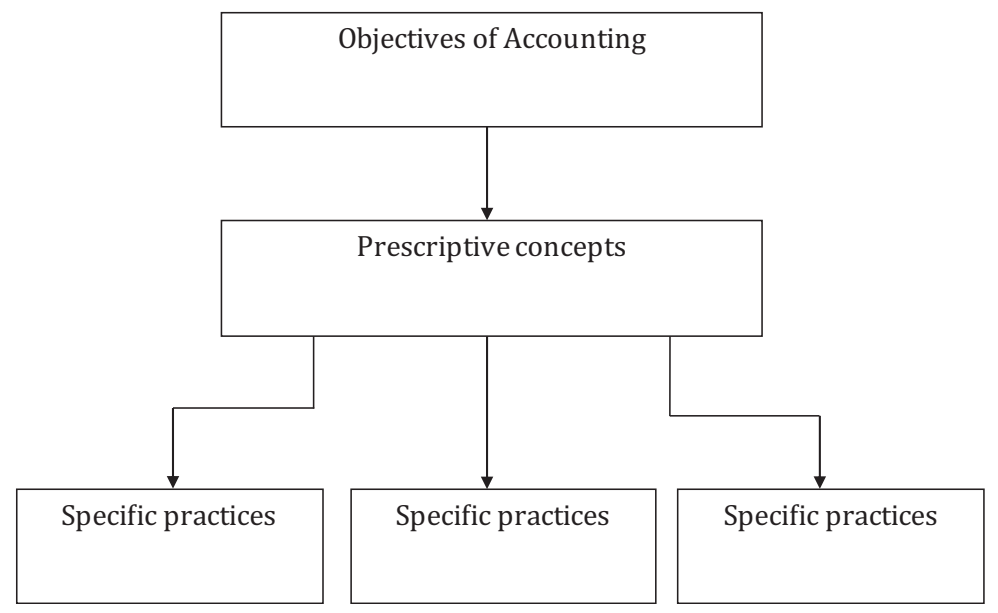

Figure 2. Prescriptive approach or top-down approach.

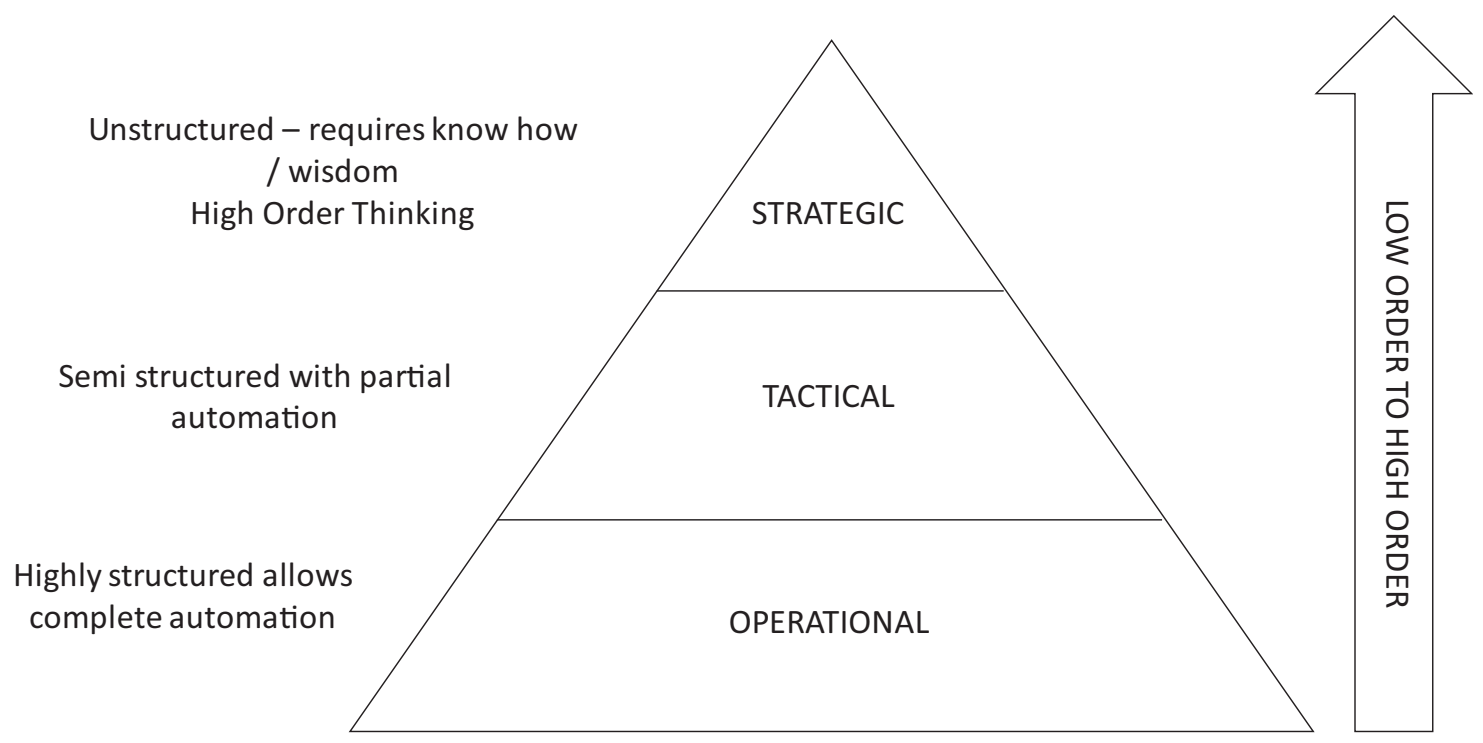

Figure 3. From descriptive to prescriptive roles. 
Table 1. Classroom technologies for digital skills.

\begin{tabular}{|l|l|l|}
\hline Items & Classroom technologies for future accountants & Mapped to existing curriculum \\
\hline 1 & SAP (ERP- enterprise resource planning) & Yes - partially \\
\hline 2 & IBM Cloud & Not traceable \\
\hline 3 & Bloomberg & Not traceable \\
\hline 4 & Microsoft Dynamics 365 & Not traceable \\
\hline 5 & XBRL (Extensible Business Reporting Language) & Not traceable \\
\hline 6 & Idaciti & Not traceable \\
\hline 7 & Aura and e-audit & Not traceable \\
\hline 8 & DMS (document management system) & Not traceable \\
\hline 9 & AIS (accounting information systems) & Not traceable \\
\hline 10 & Cyber security and trusted computing & Not traceable \\
\hline 11 & CEPS (cryptocurrencies and electronic payment systems) & Not traceable \\
\hline
\end{tabular}

Table 2. Description of classroom technologies.

\begin{tabular}{|c|c|}
\hline $\begin{array}{l}\text { Classroom technologies for future } \\
\text { accountants }\end{array}$ & Brief description \\
\hline $\begin{array}{l}\text { SAP (ERP- enterprise resource } \\
\text { planning) }\end{array}$ & $\begin{array}{l}\text { SAP FICO (FI - SAP Finance and CO - SAP Control) is a core module in the } \\
\text { SAP ERP Central Component. It describes cost elements, cost centers, } \\
\text { profit centers (handles cost data related to line of business), profitability } \\
\text { analysis, product costing and internal orders. }\end{array}$ \\
\hline IBM Cloud & $\begin{array}{l}\text { IBM provides educators with software and courseware using its cloud } \\
\text { infrastructure. This includes data gathering, sharing, computation, } \\
\text { processing and simulation. Students can experiment with what-if } \\
\text { analysis and virtual simulations. }\end{array}$ \\
\hline Bloomberg & $\begin{array}{l}\text { Bloomberg (supported by Classroom Inc.) is a non-profit online } \\
\text { educational service. Bloomberg includes simulations and technology } \\
\text { tools for banking, economics, finance and accounting. }\end{array}$ \\
\hline Microsoft Dynamics 365 & Microsoft Dynamics is a combination of ERP and CRM. \\
\hline $\begin{array}{l}\text { XBRL (Extensible Business Reporting } \\
\text { Language) }\end{array}$ & $\begin{array}{l}\text { XBRL is based on XML (Extensible Markup Language) which is a standard } \\
\text { protocol for Internet communication. It is designed to allow financial and } \\
\text { non-financial data to be exchanged for business reporting. }\end{array}$ \\
\hline Idaciti & $\begin{array}{l}\text { Idaciti makes global financial data usable, accessible and shareable. It } \\
\text { can also be used for XBRL financial datasets. }\end{array}$ \\
\hline Aura and e-audit & $\begin{array}{l}\text { Aura and e-audit specifically support competencies for the area of audit } \\
\text { in the digital age. }\end{array}$ \\
\hline $\begin{array}{l}\text { DMS - document management } \\
\text { system }\end{array}$ & $\begin{array}{l}\text { In the area of taxation competencies for the digital age, DMS is highly } \\
\text { recommended. }\end{array}$ \\
\hline $\begin{array}{l}\text { Accounting information systems } \\
\text { (AIS) }\end{array}$ & $\begin{array}{l}\text { The AIS module includes six major components: personnel, hardware, } \\
\text { software, procedure, stored data, procedures and internal controls. }\end{array}$ \\
\hline $\begin{array}{l}\text { Cyber security and trusted } \\
\text { computing }\end{array}$ & $\begin{array}{l}\text { One very key area that institutions must prepare their students for is the } \\
\text { area of trusted computing and cyber security. }\end{array}$ \\
\hline $\begin{array}{l}\text { Cryptocurrencies and electronic } \\
\text { payment systems (CEPS) }\end{array}$ & $\begin{array}{l}\text { Another area that has heavily impacted movement of funds and cash } \\
\text { flow is electronic payment methods. }\end{array}$ \\
\hline
\end{tabular}

interview took about 10 minutes for each person. We prompted the respondents to talk about the level of digital awareness among instructors and express freely on what were challenges that they faced in updating existing curriculum. We took about 5 days to collect the information needed. Notes were taken during the sessions.

Ethical approval

Ethical approval was obtained from the research management center at the university. Researchers had to first submit the title of the project, what the author planned to do for the interviews and details of study objectives. The officer at the 
research management center after reviewing the documents will then issue a letter of clearance for the data collection to be carried out. The approval letter was then obtained, and the reference number of this letter is EA1212021. Consent was obtained verbally prior to the interview and only respondents who were agreeable to be interviewed were approached. The reason for this was this was done in conjunction to a digital transformation workshop in which academics were allowed to express themselves freely about issues and challenges with regards to the teaching curriculum. The review board approved this as it was on voluntary basis.

\section{Results}

Awareness of emerging technologies for teaching

Table 3 below shows how much instructors were aware of tools that could be used to teaching emerging arrears. For this section we interviewed 52 people inclusive of subject matter experts and instructors. We selected those who had at least 5 years of teaching experience. In total, $58 \%$ of educators were not aware about most of the technologies discussed earlier. ${ }^{11}$ Among those who said they were aware, $23 \%$ had only superficial knowledge. For instance, some instructors did not know that Bloomberg Lab provided datasets that could be used for big data and predictive analytics.

\section{Antecedents of implementing classroom technologies}

Interviewees were requested to rank order factors for the implementation of emerging teaching technologies in the accounting curriculum (see Table 4). Specific reasons that were listed included: 1) training on specific technologies; 2) cost for software licensing; 3) technological resources available (computer labs and hardware); 4) compliance on ministry and accounting body standards; 5) program sustainability; and 6) others.

The most significant factor was assigned six points, followed by the second most significant value with five points and so on. The results show the overall ranking of the reasons that contributed to the antecedents of classroom technology implementation. Data shows that training on specific technologies was the most significant contributor.

Table 3. Technology awareness among instructors.

\begin{tabular}{|l|l|l|l|}
\hline $\begin{array}{l}\text { Level } \\
\text { of awareness }\end{array}$ & Working experience & Frequency & Cumulative percent \\
\hline Aware & $5-6$ years & 6 & $\mathbf{2 3 \%}$ \\
\hline 5-7 years & 4 & \\
\hline > 8 years & 2 & $\mathbf{7 7 \%}$ \\
\hline Not aware & $5-6$ years & 11 & \\
\hline $5-7$ years & 14 & \\
\hline$>8$ years & 15 & \\
\hline Total & $\mathbf{5 2}$ & \\
\hline
\end{tabular}

Table 4. Antecedents for classroom technology implementation.

\begin{tabular}{|c|c|c|c|c|}
\hline Criteria & Factors & $\begin{array}{l}\text { Rank } \\
r\end{array}$ & $\begin{array}{l}\text { Aggregate } \\
n\end{array}$ & $\begin{array}{l}\text { Percentage } \\
\%\end{array}$ \\
\hline Most significant & training on specific technologies & 6 & 108 & 22.5 \\
\hline $2^{\text {nd }}$ most significant & cost for software licensing & 5 & 85 & 21.3 \\
\hline $3^{\text {rd }}$ most significant & technological resources available & 4 & 60 & 18.8 \\
\hline $4^{\text {th }}$ most significant & $\begin{array}{l}\text { ministry and accounting body standards } \\
\text { compliance }\end{array}$ & 3 & 39 & 16.3 \\
\hline $5^{\text {th }}$ most significant & program sustainability & 2 & 10 & 6.3 \\
\hline \multirow[t]{2}{*}{ Least important } & Others & 1 & 2 & 2.5 \\
\hline & & & 80 & 100 \\
\hline
\end{tabular}


Challenges related to implementation of classroom technologies

Table 5 highlights the overall ranking of further issues faced by IHL with regards to the inclusion of classroom technologies into the curriculum. The most important factor was assigned four points, followed by three points for the second most important factor and so on.

Hypothesis testing

Table 6 summarizes key hypotheses that were formulated to facilitate this study. In this hypothesis, the objective is to find out whether the implementation of digital content is desirable, the impact of regulatory requirements and will it improve job possibilities significantly.

\section{Table 5. Challenges for technology implementation.}

\begin{tabular}{|l|l|l|l|l|}
\hline Performance evaluation & Challenges & $\begin{array}{l}\text { Rank } \\
\boldsymbol{r}\end{array}$ & $\begin{array}{l}\text { Aggregate } \\
\boldsymbol{n}\end{array}$ & $\begin{array}{l}\text { Percentage } \\
\mathbf{\%}\end{array}$ \\
\hline Most important & Cost to the university & 4 & 100 & 31.3 \\
\hline $\mathbf{2}^{\text {nd }}$ most important & Retraining staff to be competent & 3 & 75 & 31.3 \\
\hline $\mathbf{3}^{\text {rd }}$ most important & Realignment of course structure & 2 & 40 & 25 \\
\hline $\mathbf{4}^{\text {th }}$ most important & Management and peer support & 1 & 10 & 12.5 \\
\hline & & & $\mathbf{8 0}$ & $\mathbf{1 0 0}$ \\
\hline
\end{tabular}

Table 6. Hypotheses.

Hypothesis 1 Digital content is significant for the accounting curriculum

Hypothesis 2 Regulatory requirements and program standards have a significant relationship with the inclusion of technological content

Hypothesis 3 Technological competency is highly desirable among potential employers

Table 7. Response to necessity of digital content.

\begin{tabular}{|l|l|l|l|}
\hline & Frequency & Percentage \\
\hline Valid & Yes & 62 & $78 \%$ \\
\hline & No & 18 & $22 \%$ \\
\hline
\end{tabular}

Table 8. Response to digital content yielding benefits.

\begin{tabular}{|l|l|l|l|}
\hline & Frequency & Percentage \\
\hline Valid & Yes & 72 & $90 \%$ \\
\hline & No & 8 & $10 \%$ \\
\hline
\end{tabular}

Table 9. Response to digital content as standard practice.

\begin{tabular}{|l|l|l|l|}
\hline & Frequency & Percentage \\
\hline Valid & Yes & 60 & $75 \%$ \\
\hline & No & 20 & $25 \%$ \\
\hline
\end{tabular}


Table 10. Regulatory requirements have significant relationship with digital inclusion.

\begin{tabular}{|l|l|l|l|}
\hline & Frequency & Percentage \\
\hline Valid & Yes & 71 & $89 \%$ \\
\hline & No & 8 & $11 \%$ \\
\hline
\end{tabular}

Table 11. Competency desired by employers.

\begin{tabular}{|l|l|l|l|}
\hline & & Frequency & Percentage \\
\hline Valid & Yes & 74 & $92.5 \%$ \\
\hline & No & 6 & $7.5 \%$ \\
\hline
\end{tabular}

The questions that were developed to support the hypothesis are:

Hypothesis 1 - digital content is significant for the accounting curriculum

- Do you think digital content inclusion is necessary?

- Will digital content inclusion yield benefits to accounting graduates?

- Digital content inclusion should be standard practice.

Overall, $78 \%$ of the experts agree that digital content is necessary, $90 \%$ of the respondents agree that digital content will yield benefits to accounting graduates, and lastly, $75 \%$ of the respondents agree that this should be standard practice. In this context, the hypothesis that digital content is significant for improved accounting curriculum can be accepted.

Hypothesis 2 - regulatory requirements and program standards have a significant relationship with the inclusion of technological content

Out of 80 experts interviewed, $89 \%$ agree that regulatory requirements have a significant relationship with the inclusion of technology content. Therefore, this hypothesis can be accepted as well.

Hypothesis 3-Technological competency is highly desirable among potential employers

Out of 80 respondents, $92.5 \%$ agree that competency requirement among potential employers has a significant relationship with the inclusion of technology content in the curriculum. Therefore, this hypothesis can be accepted as well.

\section{Conclusions}

Results highlight that there is a significant mismatch of what is needed with what is being taught at universities today. Our hypothesis on technology competency, program standards and digital content required supports this as well. Insights derived from the mapping of existing syllabi enabled us to understand the lack of digital inclusion described earlier in the teaching pedagogy. In summary the findings helped us to provide suggestions as to how universities can improve existing curriculum offered to students. This included eleven essential areas of know-how can be fairly distributed across subjects from year one to year four for a four-year degree program. We are confident that changes made to the program structure and curriculum will definitely produce future ready graduates.

\section{Data availability}

Figshare: FinTech What Should be Taught Really? https://doi.org/10.6084/m9.figshare.14871168.v1. ${ }^{11}$

This project contains the following underlying data:

- DataSet FINTECH.xlsx (Dataset includes responses that were documented during the Interview of panel experts, academicians, program counselors, curriculum experts, program coordinators, subject experts, industry advisory 
panel and practitioners. A total of 15 institutions have been listed and categorically labelled as antecedents, challenges and hypothesis.)

Data are available under the terms of the Creative Commons Zero "No rights reserved" data waiver (CC0 1.0 Public domain dedication).

1. Arner DW, Barberis JN, Buckley RP: The Evolution of Fintech: A New Post-Crisis Paradigm? SSRN Electronic J. 2015.

$$
\text { Publisher Full Text }
$$

2. Samaduzzaman M: Blockchain: Future of Accounting Education. Asian J Finance Accounting. 2020; 12(2): 14-27. Publisher Full Text

3. Muthaiyah S: Blockchain for Audit Provenance and Trust: Push Factors, Value Creation and Challenges. Int J Auditing Accounting Studies. Academic Open Access Publishing; 2020; Vol 1(1), pg 13-25.

4. Yoon S: A study on the transformation of accounting based on new technologies: Evidence from Korea. Sustainability. 2020; 12(20): 8669.

5. Tuncay E: Effective use of cloud computing in educational institutions. Proscenia Social and Behavioral Sciences. 2010; 2 938-942.

Publisher Full Text

6. Lam M: Neural network techniques for financial performance prediction: integrating fundamental and technical analysis. Decision Support Systems. 2004; 37(4): 567-581.

Publisher Full Text
7. Calderon TG, Cheh J: A roadmap for future neural research in auditing and risk assessment. Int J Accounting Information Systems. 2002; 3: 203-236. Publisher Full Text

8. Hakim RRC: Are accounting graduates prepared for their careers? A comparison of employees' and employers' perceptions. Global Review of Accounting and Finance. 2016; 7(2): $1-17$. Publisher Full Text

9. Aryanti C, Adhariani D: Students' perceptions and expectation gap on the skills and knowledge of accounting graduates.J Asian Finance Economics Business. 2020; 7(9): 649-657. Publisher Full Text

10. Anastasiou EF: Accountancy Graduates' Employability: Narrowing the Gap between Employers' Expectations and Students' Perceptions-The Role of HE. University of Derby (United Kingdom); 2021.

11. Muthaiyah S, Phang K, Sembakutti S: FinTech What Should be Taught Really?. figshare. Dataset. 2021.

Publisher Full Text 


\section{Open Peer Review}

\section{Current Peer Review Status:}

\section{Version 1}

Reviewer Report 11 January 2022

https://doi.org/10.5256/f1000research.76488.r98790

(C) 2022 Benjamin S. This is an open access peer review report distributed under the terms of the Creative Commons Attribution License, which permits unrestricted use, distribution, and reproduction in any medium, provided the original work is properly cited.

\section{Samuel Jebaraj Benjamin}

School of Accounting, Finance and Economics, University of Waikato, Hamilton, New Zealand

Comments;

This is an interesting study and timely. Fintech and/or digital skills are highly important for accounting and finance graduates, but is still lacking in their undergraduate syllabus. This study has the potential to contribute to our understanding of this issue. The following are the main issues that the paper needs to address in order to ensure its rigour and contribution are noteworthy.

1. You do not define the scope of digital transformation or fintech. Technological areas such as AI, blockchain, cloud computing, ANN, etc. are thrown into the mix without clear coherence with the key focus of the paper. It is hard to follow through chronologically the flow of arguments and paragraph 1 of the Literature Review seems to have been written haphazardly. I suggest to more clearly outline the arguments and motivations of the paper with the proper citations and focus.

2. "Today's accounting curriculum is focused on descriptive accounting (see Figure 1). Prescriptive accounting is rather limited, with the exception of managerial and cost accounting only (see Figure 2). For example, assets are still recorded and maintained at cost which is not aligned to fair value accounting principles" ;

The relevancy of the statement above is unclear. You are talking about an accounting treatment issue and this has got nothing to do with the fintech or digitalization that your study is concerned with.

3. I do not see the relevancy of Figure 1 and 2 towards the aims of this study.

4. It is unclear why many of the items mentioned in Table 1 were identified, as no prior discussion about it is made in the preceding sections. Only concepts, such the ones I mentioned in Point 1 above, are discussed, but, in Table 1, most of the areas are entirely new in the paper and not previously defined nor addressed. Table 2 should appear before Table 1. However, it is still unclear if how the 'technologies' mentioned in Tables 1 and 2 fit 
under the grand idea of 'fintech' or some of the sub-areas that you mentioned in paragraph 1 of the Literature Review.

5. Hypotheses testing approach and how the conclusions are arrived (i.e., valid or not valid) for each hypotheses have to explained.

6. Is the scope of your study confined to only the undergraduate syllabus in accounting and finance or include postgraduate? You need to clearly indicate this.

Is the work clearly and accurately presented and does it cite the current literature? Partly

Is the study design appropriate and is the work technically sound? Yes

Are sufficient details of methods and analysis provided to allow replication by others? Partly

If applicable, is the statistical analysis and its interpretation appropriate? Partly

Are all the source data underlying the results available to ensure full reproducibility? Yes

Are the conclusions drawn adequately supported by the results?

Yes

Competing Interests: No competing interests were disclosed.

Reviewer Expertise: Accounting, finance

I confirm that I have read this submission and believe that I have an appropriate level of expertise to confirm that it is of an acceptable scientific standard.

Reviewer Report 23 December 2021

\section{https://doi.org/10.5256/f1000research.76488.r93576}

(C) 2021 Sambas I. This is an open access peer review report distributed under the terms of the Creative Commons Attribution License, which permits unrestricted use, distribution, and reproduction in any medium, provided the original work is properly cited.

\section{Indrawati Sambas}

Faculty Economics \& Business, Telkom University, Bandung, Indonesia

I think this paper is good and is an imperative addition to the literature. I found that the work was 
clearly and accurately presented, and it cites the current literature. The study design was appropriate and the work is technically accepted. The work should elaborate more on the explanation of Figure 1 and 2, to make it clearer. The writers have to expand on how the hypotheses are accepted or rejected. What is the threshold? Please cite business research books such as Sekaran (2016). It is better if the verbatim interview can be accessed, to make the explanation of the findings clearer.

\section{References}

1. Sekaran U, Bougie R: Research Methods For Business. Wiley. 2016.

Is the work clearly and accurately presented and does it cite the current literature? Yes

Is the study design appropriate and is the work technically sound? Partly

Are sufficient details of methods and analysis provided to allow replication by others? Yes

If applicable, is the statistical analysis and its interpretation appropriate? Yes

Are all the source data underlying the results available to ensure full reproducibility? Yes

Are the conclusions drawn adequately supported by the results?

Yes

Competing Interests: No competing interests were disclosed.

Reviewer Expertise: Customer adoption in services based on technology

I confirm that I have read this submission and believe that I have an appropriate level of expertise to confirm that it is of an acceptable scientific standard. 
The benefits of publishing with F1000Research:

- Your article is published within days, with no editorial bias

- You can publish traditional articles, null/negative results, case reports, data notes and more

- The peer review process is transparent and collaborative

- Your article is indexed in PubMed after passing peer review

- Dedicated customer support at every stage

For pre-submission enquiries, contact research@f1000.com 